\title{
A Internet e O SeU aCesso pelos estudantes em PERÍODO ESCOLAR: À PROCURA DE UMA EPISTEMOLOGIA COMPORTAMENTAL E PSICOLÓGICA EM AMBIENTE ESCOLAR
}

THE INTERNET AND ITS ACCESS BY STUDENTS IN SCHOOL: LOOKING FOR A BEHAVIORAL AND PSYCHOLOGICAL EPISTEMOLOGY IN A SCHOOL ENVIRONMENT

DOI: 10.23926/RPD.2526-2149.2020.v5.n2.p1459-1476.id697

\section{Marco Aurélio \\ Nicolato Peixoto \\ Doutorado em Educação em \\ Ciências e Matemática \\ (UFMT) \\ Professor do Instituto \\ Federal de Minas Gerais \\ (IFMG) \\ marco.peixoto@ifmg.edu.br}

\section{Lucas Ribeiro Lima}

Tecnólogo em

Processamento de dados

Servidor do setor de

Tecnologia e Informática do

Instituto Federal de Minas

Gerais (IFMG)

$\underline{\text { lucas.lima@ifmg.edu.br }}$

\section{Cirlande Cabral da Silva}

Pós doutorado em Educação em Ciências (UFSM)

Professor do Instituto

Federal do Amazonas (IFAM)

cirlandecabral@gmail.com
Resumo: Novas tecnologias como a utilização da internet e do telefone celular alcançam cada vez mais a sala de aula. O objetivo desse artigo é compreender como ocorre a construção de uma epistemologia psicológica e comportamental em ambiente escolar. A metodologia utilizada se baseia na técnica de observação participante e pesquisa documental no firewall da rede de internet utilizada em uma escola, investigando o dia letivo em suas 24 horas, nos três, dos cinco dias de aulas semanais. Os resultados indicam que os horários de aula são justamente aqueles em que os estudantes mais acessam a rede, mesmo havendo proibição em contrário. Percebe-se que é tarefa educativa mediar a formação de hábitos mentais em relação ao tempo para o acesso às tecnologias sem se retirar o seu livre arbítrio que vem sendo exercido, através de burla à proibição imposta.

Palavras-chave: Novas tecnologias. Educação. Internet na educação. Formação de professores.

\begin{abstract}
New technologies such as the use of the internet and the cell phone are increasingly reaching the classroom. The objective of this article is to understand how the construction of a psychological and behavioral epistemology occurs in a school environment. The methodology used is based on the technique of participant observation and documentary research in the firewall of the internet network used in a school, investigating the school day in its 24 hours, in the three, of the five days of weekly classes. The results indicate that the class schedules are precisely those in which students access the network the most, even if there is a prohibition to the contrary. It is perceived that it is an educational task to mediate the formation of mental habits in relation to the time for access to technologies without removing their free will that is being exercised, by circumventing the imposed prohibition.
\end{abstract}

Keywords: New technologies. Education. Internet in education. Teacher training. 


\section{INTRODUÇÃO}

Na maioria dos estados brasileiros existem leis que proíbem o uso dos celulares em salas de aula, tendo como justificativa para todas elas, em seus projetos de proibição, que esta medida se justifica, tendo em vista que o uso do telefone pode desviar a atenção dos alunos, possibilitar fraudes durante as avaliações e provocar conflitos entre professores e alunos, alunos entre si, influenciando o rendimento escolar. Se por um lado, a tecnologia pode servir de apoio às ações educacionais, por outro o seu uso exacerbado pode efetivamente se tornar um empecilho.

Parece consenso entre os docentes e educadores de uma forma geral que os celulares devem ser proibidos em sala de aula, tendo em vista a assegurar a essência do ambiente escolar, sem que nada possa competir ou desviá-lo desse objetivo. Observa-se ser este um assunto com ampla concordância nas falas dos profissionais evidenciadas em conselhos de classe, em comentários após as aulas e outras reuniões. Mesmo porque, se não estabelecida a proibição nas reuniões escolares, existe legislação proibitiva que assim o determina como é o caso dos estados de Rio de Janeiro, São Paulo e Distrito Federal como importantes referências nacionais.

No entanto, independente da discussão pedagógica acerca do uso dos telefones celulares em escolas, cabe uma reflexão no sentido de se ponderar em que medida estas ações/leis proibitivas tem efetivamente provocado o efeito esperado.

Embora se perceba a possibilidade do uso de celulares em sala de aula como nos artigos de Chiossi e Costa (2018) e de Júnior (2018) existem diversas dissertações e teses, com grande quantidade de trabalhos produzidos sobre o tema das novas tecnologias na educação. Trabalhos relacionando as tecnologias com as metodologias educativas tem se intensificado sobremaneira na última década, desbravando um amplo campo de pesquisa que se descortina e possuem "aderência" ao tema desse trabalho, apesar de não ser o alvo específico desse artigo.

No entanto, observa-se ainda a prevalência do embate teórico em relação aos temas afeitos às novas tecnologias na educação, não ocorrendo ainda uma condição generalizada de uso das tecnologias em sala de aula alimentada por esses debates e pesquisas na educação. São mais frequentes as dissertações acerca das novas tecnologias como objeto de estudo no campo didático-pedagógico. É certo que mesmo com os avanços obtidos nas pesquisas em educação, ainda há muito a ser abordado vinculando a utilização da Internet e sua interconexão com a educação. Notam-se amplos campos associativos a serem melhor estudados e que podem configurar uma interpenetração, por exemplo, dos aspectos educacionais e tecnológicos do ensino e da aprendizagem, integrados aos aspectos cerebrais e psicológicos do homem, enquanto ser individual e social. É preciso que estas pesquisas continuem avançando, a fim de 
se configurar uma epistemologia robusta capaz de delinear diretrizes que possam abarcar toda a extensão das implicações que a esses temas podem estar vinculados.

Não se trata, portanto, de uma questão mais rasa na qual se permite, ou não, o uso do telefone celular em sala de aula pelos discentes, mas, sobretudo de entender, como esta cultura modifica a mente e o contexto educacional. Estudos mais apurados podem demandar uma nova metodologia educacional que tenha o seu foco e desenvolvimento prioritariamente na mente e nos processos formativos de conceitos do estudante como um todo. Isto porque é preciso que a mente, seja entendida e educada, no sentido de que possa conviver harmonicamente com a realidade, seja ela analógica ou digital; seja ela física ou virtual, pois, nesse "contexto novo", ela se consolida com peculiar entendimento e autonomia, cujos processos podem não ser tão bem conhecidos.

É neste sentido que é possível deslocar e se distinguir este trabalho de outros trabalhos de pesquisa ligados esse tema, pois, sugere de antemão, a necessidade de desdobramentos mais agudos em relação às novas tecnologias e o contexto educacional como um todo que superam no campo acadêmico, aspectos legais proibitivos.

Agrega-se ao debate, portanto, o panorama complexo em que são inseridas "as proibições escolares" e que, se mal refletidas e utilizadas na escola, podem solapar as discussões ao mesmo tempo em que fratura a tênue relação entre a escola e um "novo mundo" apresentado, sobretudo, pelas novas tecnologias.

Essa condição pode demandar uma nova abordagem pelos profissionais de educação e uma "nova educação" mais focada na aquisição de hábitos mentais pelos discentes, o que vai além de apenas incorporar, ou não, as novas tecnologias.

Destaca-se também o fato de que, independente de metodologias pedagógicas e afeito à própria configuração do pensamento moderno, os aparatos tecnológicos têm sido trazidos para as salas de aula espontaneamente pelos estudantes, indiferente às proibições que não dão conta de deter este processo.

Neste sentido, a discussão parece não se tratar, pois, de ser a favor ou contra a utilização das novas tecnologias atreladas à educação, ou de ser a favor ou contra uma metodologia específica que inclua, ou não, as novas tecnologias. Trata-se, sobretudo, de perceber a nova configuração social advinda das novas tecnologias, bem como os desafios e a ampliação mental que elas podem proporcionar.

É preciso neste "contexto novo", o entendimento desse movimento, dessa "nova natureza", que "bate à nossa porta" e altera o psicológico, o biológico e o social da vida humana, 
colocando-nos a todos, diante de uma mesma realidade que supera, por certo, o ambiente unicamente escolar.

Diante do panorama descrito, o objetivo desse artigo é compreender como ocorre a construção de uma epistemologia psicológica e comportamental em ambiente escolar.

\section{OS ASPECTOS CEREBRAIS E O PROCESSO DE ENSINO APRENDIZAGEM}

O início do Século XX ficou conhecido como a década do cérebro. Nunca outrora, se avançara tanto nos conhecimentos sobre o cérebro com o uso de imagens que permitiram mapear o funcionamento cerebral, testes químicos e entendimento do papel de neurotransmissores, dentre outros. Mesmo assim, muitos processos cerebrais continuam ainda sem explicação. $\mathrm{O}$ acesso à memória, por exemplo, seja ela de curto ou de longo prazo, parece ser direcionado pela concentração que a acessa. Talvez por isso, exista uma forte preocupação com a preservação da concentração ligada aos conteúdos das disciplinas em ambientes escolares. Sabe-se que, apenas uma pequena parte da capacidade cerebral é utilizada conscientemente, por isso, desconhecemos todo o nosso potencial cerebral. Ainda não foi efetivamente sistematizada uma metodologia escolar, capaz de um procedimento amplo e único, que permita de maneira generalizada, aumentar a concentração dos estudantes, ao mesmo tempo em que seja capaz de expandir a utilização consciente do cérebro. Por certo, a área pedagógica que melhor interface possui com este objetivo de expansão da consciência cerebral, é a área da didática, no sentido de que busca proporcionar atrelado ao ensino, os estímulos adequados para se manter a concentração e a aprendizagem.

Assim sendo, na ausência de um entendimento maior acerca dos processos que relacionam o cérebro e a concentração, os "mecanismos mentais" que dão conta desse processo, vão se estruturando naturalmente, sem muito conhecimento dos artífices da escola e em reciprocidade à realidade vivida no ambiente escolar. Mesmo porque, "o cérebro adulto modifica-se com o passar do tempo e talvez não seja exagerado dizer que nunca se observa duas vezes o mesmo cérebro [...]" (JEANNEROD, 2005, p.48).

É inerente à sobrevivência humana, o domínio das condições naturais de vida e a adaptação do indivíduo ao meio, sendo que a natureza seleciona e favorece aos mais adaptados (Darwin, 1859). "A plasticidade sináptica verificada durante a aprendizagem no decurso do desenvolvimento e no estado adulto, esculpe o cérebro de cada um de nós", sendo que "a educação, a experiência, a formação fazem de cada cérebro uma obra única" (JEANNEROD, 2005, p.51). Não obstante, segundo Damásio e Motta (2015), “[...] o processo de construção do 
conhecimento requer um cérebro, assim como requer as propriedades sinalizadoras com as quais os cérebros conseguem montar padrões neurais e formar imagens" (DAMÁSIO e MOTTA, 2015, p. 28). Ampliando as considerações baseadas no conhecimento biológico, na qual sabe-se que a capacidade de adaptação garante a sobrevivência dos seres, a aprendizagem é eminente e naturalmente um processo adaptativo. Considerando que

[...] el aprendizaje es un proceso por el que los organismos modifican su conducta para adaptarse a las condiciones cambiantes e impredecibles del medio que los rodea $[\ldots]$ e "[...] cuanto más cambiante es el entorno, más plástica debe ser la conducta [...] (MORGADO, 2011, p. 20).

Desta forma, considerando que a educação interfere diretamente nos processos adaptativos, neuronais e cognitivos, é plausível que o papel do educador exija também atenção e capacidade crítica no sentido de que,

[...] não se pode permitir que as Novas Tecnologias sejam disseminadas como um resultado de pressão das empresas produtoras de computadores, ou dos programas por elas utilizados, ou mesmo aproveitando restos de material bélico (OLIVEIRA, 2001, p. 10).

Tal situação tenciona o processo educacional e eleva a responsabilidade dos profissionais da educação para além de um aspecto meramente proibitivo que carece de melhor delineamento acadêmico.

\section{AS NOVAS TECNOLOGIAS E A ESCOLA: UM PANORAMA NOVO E COMPLEXO}

É possível perceber que as condições naturais de vida no planeta se alteraram radicalmente com o advento das novas tecnologias, principalmente à partir da década do 1980 em que se iniciou um ciclo de alterações e sobreposições tecnológicas intenso, estabelecendo um “[...] novo sistema de comunicação que transforma radicalmente o espaço e o tempo, alterando as dimensões fundamentais da vida humana (CASTELLS, 2017, p.458).

Hoje é raro o jovem que não possui um telefone, aparato esse que funciona, mesmo com tamanho diminuto, com capacidade muito superior aos antigos computadores. As redes sociais determinam grande parte do sucesso social das pessoas e a vida coletiva se atualiza quase que instantaneamente das novas tecnologias, configurando, segundo Lévy (2000), uma Inteligência Coletiva. Essa "inteligência coletiva”, no entendimento de Lévy (2000), se distribuí por toda a parte, de tal forma que, “[...] ninguém sabe tudo, todos sabem alguma coisa, todo o saber está na humanidade" (LEVY, 2000, p.29). Acrescenta a esta ideia que “[...] a luz do espírito brilha mesmo onde se tenta fazer crer que não existe inteligência: fracasso escolar, execução simples, subdesenvolvimento etc.” (LÉVY, 2000, p.29), sentenciando desta forma que, o juízo global 
volta-se contra quem o pronuncia. Se você cometer a fraqueza de pensar que alguém é ignorante, procure em que contexto o que essa pessoa sabe é ouro.

Sob este contexto os professores podem representar para os estudantes essa ignorância descrita por Lévy (2000), ao não perceberem esta inteligência coletiva tão comum à esses jovens que acessam o "ciberespaço". Cabe esclarecer também acerca da "inteligência coletiva", descrita por Lévy (2000), que ela é apresentada como só tendo início à partir da cultura e cresce na medida em que cresce essa cultura. Apresenta, Lévy (2000), em sua concepção, uma série de conceitos que compõe este universo, na qual se configura a "inteligência coletiva", formulando um arranjo heurístico sofisticado, que culmina neste tipo peculiar de inteligência.

Pode-se destacar a questão geográfica no sentido de que "[...] a comunicação contínua, com o digital, um movimento iniciado há muito tempo pelas técnicas mais antigas como escrita, gravação de som e imagem, o rádio a televisão e o telefone" (LÉVY, 2010, p.48), em cujo escopo se insere o conceito de "ciberespaço" na geração de uma comunicação assíncrona, quase que independente de lugares geográficos.

Agrega-se também de forma relevante a este panorama o papel da cultura, enquanto campo acadêmico de estudo, ampliando em muito o universo a ser compreendido. Isto porque os mecanismos pelos quais a cultura torna-se parte da natureza de cada pessoa foram sugeridos desde o século passado por Vygotsky, ao insistir que as funções psicológicas são um produto da atividade cerebral, defendendo "[...] a associação da psicologia cognitiva experimental com a neurologia e fisiologia" (VYGOTSKY, 1991, p. 07) e lançando as bases de uma ciência comportamental unificada. Portanto, a internalização dos sistemas de signos produzidos culturalmente provocam transformações comportamentais e estabelecem um elo entre as formas iniciais e tardias de desenvolvimento individual" (VYGOTSKY, 1991, p. 08). É certo que hoje em dia este renomado pesquisador teria um enorme campo de investigação, em agregação aos seus temas anteriores de análise, ao se investigar os impactos educativos, psicológicos e cognitivos provocados pelas Novas Tecnologias. Este campo que se amplia envolve o estudo e o entendimento dos símbolos produzidos, bem como a internalização desses símbolos, em uma realidade dita disruptiva. Realidade essa que, não segue um padrão previamente definido, nem está limitada apenas às três dimensões, como se pode observar nos "mundos virtuais" e que impacta sobremaneira os estudantes do século XXI, provocando alterações, tanto biológicas, quanto comportamentais, advindas desse "novo processo conformacional" que demanda recorrentemente investigação e aprofundamento científico. 
A conjunção de todas essas questões em um único ambiente, no caso a escola, pode gerar um panorama novo e complexo, de difícil adaptação, tanto docente, quanto discente, no que tange à vida nesse meio escolar. Faz parte do espírito de sobrevivência do jovem e de seu sucesso, prevalecer frente às novas tecnologias em um mundo cada vez mais virtual, estabelecendo segundo Castells (2017), uma forma particular de cultura, constituída nos processos de comunicação, em que não há separação entre a realidade e a representação simbólica.

Paradoxalmente, se o indivíduo ainda não conseguiu uma forma única de aumento de sua concentração, bem como da sua capacidade consciente de utilização cerebral nos processos biológicos mais internos, o mesmo pode não ter ocorrido externamente. Isto porque o jovem amplia a sua capacidade cognitiva ao acessar "memórias coletivas", muitas vezes de caráter universal, na comodidade de seu telefone que funciona nesses casos, como se fosse um "HD externo" da sua memória biológica. Tal condição permite a ele um amplo acesso, tanto a cultura coletiva da humanidade, quanto a sua própria e pessoal. Mesmo porque, “[...] a comunicação mediada pela Internet é um fenômeno social recente demais para que a pesquisa acadêmica tenha tido a oportunidade de chegar a conclusões sólidas sobre seu significado social" (CASTELLS, 2017, p.440).

Tal estado de "empoderamento" causa nas instituições de ensino, senão um dilema, um grande conflito, ao mesmo tempo em que se configura como um grande desafio. É certo que muitos professores possuem uma formação e uma orientação mental diferente daquela que possuem muitos estudantes. Desta forma, em sua concepção idiossincrática, acreditam que a desconcentração causada pelo acesso a informações não atinentes a assuntos locais que "gravitam em torno da sala de aula", podem comprometer o grau de concentração dos estudantes.

Neste sentido, pode estar em contraposição à pacificação do que se estabelece como conflituoso no cotidiano da maioria das instituições de ensino, a adoção da medida que proíbe o uso de celulares em sala de aula. Isto porque, tal proibição estabelece sanções para o uso de celulares em instituições de ensino para um público que é naturalmente contestador, o que pode estimular a rebeldia em relação a este status quo, legitimado por leis civis em realidade escolar.

Nesta perspectiva, seria esta uma medida válida e educativa, ou estaria na contramão da história moderna? Isto porque ao jovem a proibição e a oposição das antigas gerações pode soar como algo a ser transposto e burlado, dando uma motivação contraria ao que se quer nas instituições de ensino. 
A reflexão sobre estas questões anteriormente discutidas e que podem estar associadas em maior ou menor grau, à pesquisa implementada neste trabalho, levaram-nos à reflexão de que é necessário educar a mente do estudante para que ela seja utilizada no sentido de ativar as áreas cerebrais afeitas ao conhecimento, ao mesmo tempo em que se educa a consciência para o acesso às novas tecnologias, sem perder efetivamente o foco, daquilo que está sendo estudado. Este um processo lento, que exige atenção especial e pode ser comparável aos procedimentos adotados com os estudantes da educação infantil ao serem educados para a formação de hábitos, processo que ocorre ainda em tenras idades. É conhecido, portanto, o princípio da educação infantil de que, a formação de hábitos corretos em relação ao tempo são muito importantes. Neste contexto, se objetiva para o aluno que ele saiba e interiorize que, existe hora para brincar, hora para estudar, hora para comer, hora para dormir e outros momentos, que necessitam estar demarcados na rotina das crianças.

Este um processo formativo gradual, implementado desde as séries iniciais de ensino. Existe, pois, a possibilidade de que o computador/telefone celular, como algo relativamente novo na história da humanidade, demande um processo semelhante nas mentes dos estudantes que precisam se educar individualmente em relação ao uso da Novas Tecnologias em ambiente escolar.

Tal procedimento não inclui a exclusão dos aparatos tecnológicos, mas, sobretudo o saber lidar com eles nos tempos escolares. Este um "novo campo educacional" que figura acima da questão proibitiva. Mesmo porque, conforme este trabalho demonstrará, as proibições civis não têm desestimulado os jovens a utilizar os telefones nas instituições escolares. A questão que se impõe é estabelecer procedimentos que qualifiquem o acesso àquelas informações que podem contribuir mais efetivamente para a sua formação naquele momento, em detrimento, de outras ações que os conduzam a "lugares virtuais", que possam comprometer o que é ensinado naquele instante, como as redes sociais, WhatsApp, jogos virtuais, dentre outros que precisam ser disciplinados internamente.

Assim sendo, se configuram de maneira singela as seguintes perguntas: As proibições dos aparatos tecnológicos na escola, dentre eles os telefones e smartphones, tem dado conta de conter o acesso dos estudantes a esses recursos durante as aulas? Caso as proibições legais não refreiem o acesso dos estudantes à Internet durante as aulas, existe a consciência dos partícipes escolares dessa conjuntura implícita na vida escolar, independente do viés da ilegalidade em que tal condição se insere? 
Para responder a estas perguntas foi estabelecida uma pesquisa em que uma escola da rede federal de ensino com aproximadamente 1000 alunos, em sua totalidade nas 24 horas do dia (em seus três turnos de funcionamento), foi monitorada no ambiente escolar em relação ao seu acesso à Internet. Para organizar os dados foram escolhidos três dias da semana (segunda/quarta e sexta feira) no intuito de se analisar o comportamento dos estudantes, no que tange ao acesso à Internet dentro da escola.

\section{Procedimentos Metodológicos}

A metodologia utilizada contou inicialmente com o procedimento relativo à observação participante, tendo em vista que “[...] o investigador participa até certo ponto como membro da comunidade ou população pesquisada" (GERHARDT e SILVEIRA, 2009, p. 75). Assim sendo, ocorre o contato direto do pesquisador com o fenômeno observado, obtendo informações sobre a realidade dos atores sociais em seus próprios contextos. O pesquisador, mediante a técnica da observação participante, observa os fenômenos diretamente na própria realidade.

Utilizou-se também a pesquisa bibliográfica, no que tange "aos dados obtidos a partir de fontes escritas, portanto, de uma modalidade específica de documentos [...]" (GERHARDT e SILVEIRA, 2009, p. 69) para entender como se configura a tendência legislativa sobre o tema em questão.

No sentido de se perceber a realidade investigada na fonte, independente de possíveis aparências, estabeleceu-se também uma investigação de caráter exploratório documental, tendo em vista que a pesquisa documental pode ser caracterizada pelo acesso a relatórios, dados de registro, dentre outras fontes, configurando um quadro a partir de dados cientificamente autênticos, sendo esta técnica de pesquisa "[...] aquela realizada a partir de documentos" (GERHARDT e SILVEIRA, 2009, p. 69).

Desta forma, a pesquisa veio sendo registrada em diários de campo, pensada e maturada durante meses, considerando reuniões como Conselhos de Classe, o flagrante de celulares em avaliações oficiais da escola, apontamentos docentes em salas de aula, dentre outros momentos registrados que "nutriram e subsidiaram" as diretrizes contidas neste trabalho.

Desta forma, estruturou-se um procedimento de pesquisa no sentido de se buscar no "programa firewall da rede escolar", os dados relativos ao uso da Internet, tendo em vista que “[...] a Internet não é apenas a maior rede de comunicação construída pelo homem até hoje, ela é, antes de tudo, muitas coisas reunidas numa só entidade” (CRUZ, 2011, p. 126). 
Buscou-se, assim, colimar os relatórios dos sistemas utilizados com a presença de tabelas e a configuração de gráficos, a fim de se evidenciar a situação pesquisada. Destaca-se que os relatórios pesquisados geraram dados precisos e exatos em sua concatenação do acesso à Internet no ambiente escolar. Acredita-se que a pesquisa do acesso à Internet possibilitou uma ideia real do que ocorre no ambiente escolar, considerando que "[...] a Internet é a espinhal dorsal da comunicação global mediada por computadores" (CASTELLS, 2017, p. 430).

Assim sendo, foi escolhida uma escola da rede federal de ensino e monitorados aproximadamente 1000 estudantes do ensino médio e superior em três turnos e em 3/5 dos dias escolares (segunda, quarta e sexta feira) no início da terceira e última etapa letiva do campus pesquisado.

Destaca-se ainda que a Internet no campus pesquisado é franqueada aos estudantes e não restringe todos os tipos de acesso, restringindo apenas alguns sites. Essa condição dá aos estudantes a possibilidade de acesso às redes sociais, bem como alguns jogos, dentre outras possibilidades.

Para evitar o excesso de dados coletados, sendo muitos deles não contributivos aos objetivos dessa pesquisa, optou-se por sua compilação simples em gráficos que dão a nítida representação do que se pretende analisar para este trabalho de pesquisa, estando esses gráficos expostos a seguir, na área destinada aos resultados da pesquisa realizada.

\section{Resultados e Discussões}

Os resultados coletados e cuidadosamente registrados em diário de campo evidenciaram que nas aulas do Ensino Médio ocorriam apreensões de muitos celulares, principalmente em aulas nas quais os estudantes realizavam provas. Observou-se ainda em reuniões da escola que os docentes reclamaram de apontamentos dirigidos aos estudantes para guardarem os celulares durante as aulas. Nestas reclamações o celular é percebido pelos professores como um aparato altamente negativo às aulas ministradas.

A amostragem relativa a pesquisa documental, contou ainda com $100 \%$ dos estudantes, que tiveram os seus dados, acerca do uso da Internet na escola, inseridos em relatórios oficiais do setor de tecnologia e informática da instituição. Senão, vejamos:

A rede "firewall ${ }^{1}$ da escola é um dispositivo que registra os acessos à Internet no campus. Desta forma, ao pesquisar naquela, obteve-se dados compilados em gráficos e tabelas

\footnotetext{
${ }^{1}$ Um firewall é um dispositivo de segurança da rede que monitora o tráfego da Internet e pode ao monitorar a entrada e saída de acessos, "permitir" ou "bloquear" tráfegos específicos de acordo com um conjunto definido de 
acerca dos acessos à Internet, das quais escolheu-se o uso do gráfico para este trabalho, por ser de mais fácil visualização e sintetizar efetivamente aquilo que se pretende mostrar.

Assim sendo, foram gerados três gráficos relativos aos dias pesquisados em que se observou o uso da Internet a cada hora, durante todo o dia indicado. É importante para se analisar os dados gerados, firmar os horários das aulas presenciais no campus.

Dessa forma, tem-se que os horários de aulas presencias no campus pesquisado compreendem, no período vespertino, à duas aulas geminadas de 7:30 às 9:10, sendo de 9:10 às 9:30 intervalo. Depois as aulas recomeçam de 9:30, indo ininterruptamente até às 12:00 horas sem intervalos para descanso, ocorrendo apenas a troca eventual de um ou outro professor. O intervalo para almoço vai de 12 horas às 13:50 horas e recomeçam as aulas do período matutino às 13:50, indo até 15:10. Há intervalo de 15:10 até 15:30. As aulas da tarde novamente se iniciam às 15:30 e vão até 18 horas sem pausas para descanso, ocorrendo apenas a troca de professores. Por fim, no período noturno, às aulas se iniciam às 18:50 horas e vão até 20:30. De 20:30 até 20:50 ocorre um intervalo e de 20:50 até 22:30 ocorrem as aulas finais do dia.

Feitas as considerações, para a segunda feira foi gerado o gráfico (Figura 1), no que tange ao uso da Internet no campus pesquisado.

Figura 1 - Gráfico relativo ao uso da Internet no dia 10 de setembro de 2018 (Segunda feira) em um Campus do Instituto Federal

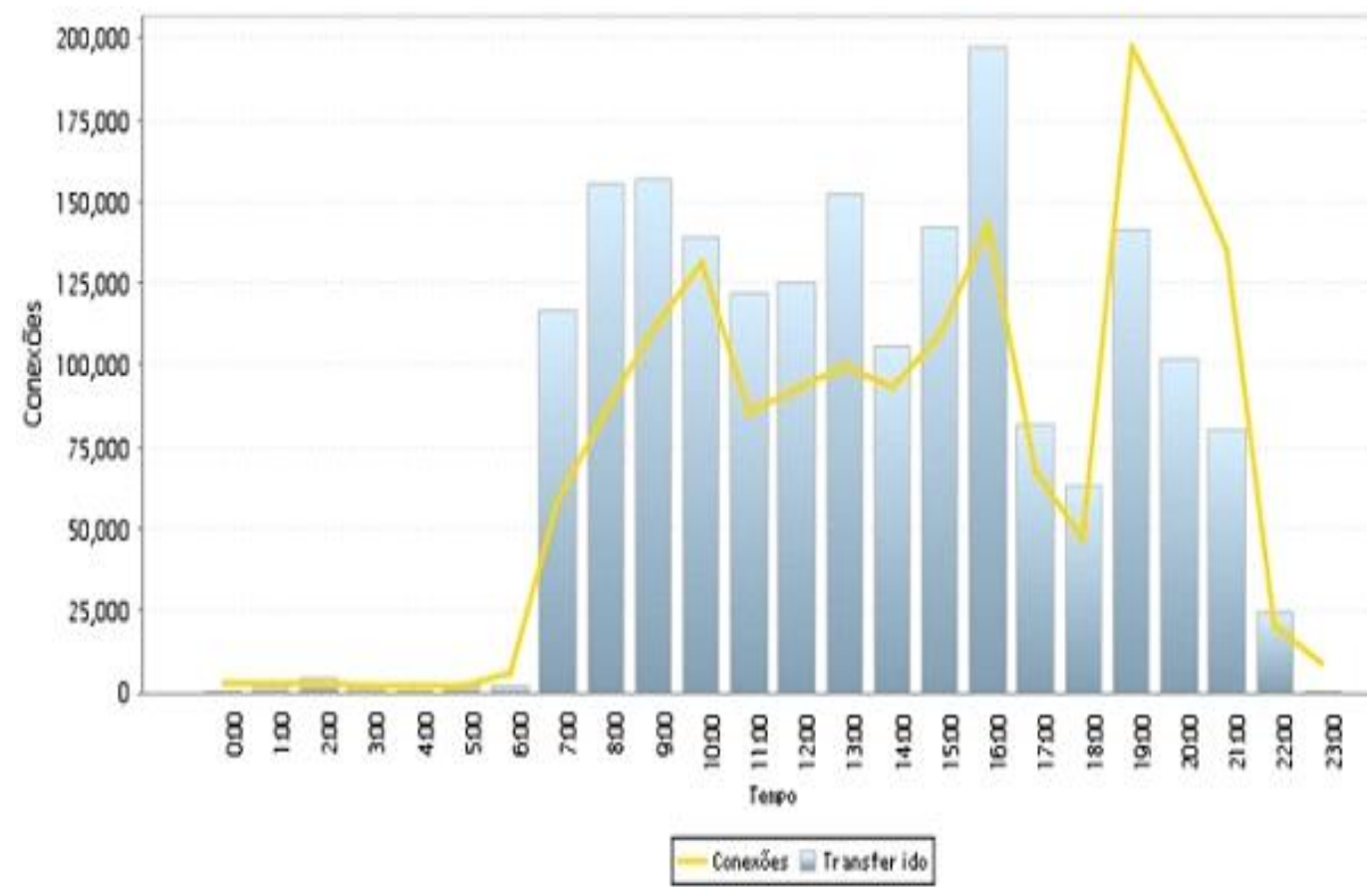

Fonte: Autores, 2020.

regras de segurança. Descrição inspirada no site: https://www.cisco.com/c/pt br/products/security/firewalls/whatis-a-firewall.html. Acesso em 24/09/2018. 
Observam-se (Figura 1) picos de utilização da Internet de 08 às 09 horas, em período de aula, compreendendo um tempo cronológico em que, segundo a proibição imposta pela escola, os telefones celulares deveriam estar efetivamente desligados. Depois ocorre novo pique de utilização às 13 horas, em momento pós almoço e um novo pique de utilização ocorrendo às 16 horas, quando da mesma forma ocorrida durante a manhã, os estudantes deveriam também estar em aulas presenciais e com os telefones desligados. Pode-se perceber a ocorrência do mesmo fenômeno à noite, onde o pico de uso é alcançado às 19 horas, durante o horário das aulas no período noturno.

Observou-se, pois, um padrão em que, justamente no período das aulas, ocorrem aumento nos acessos à Internet no campus. Passamos agora à análise dos dados obtidos na quarta feira e que compilados deram ensejo ao gráfico (Figura 2).

Figura 2 - Gráfico relativo ao uso da Internet no dia 12 de setembro de 2018 (Quarta feira) em um campus do Instituto Federal

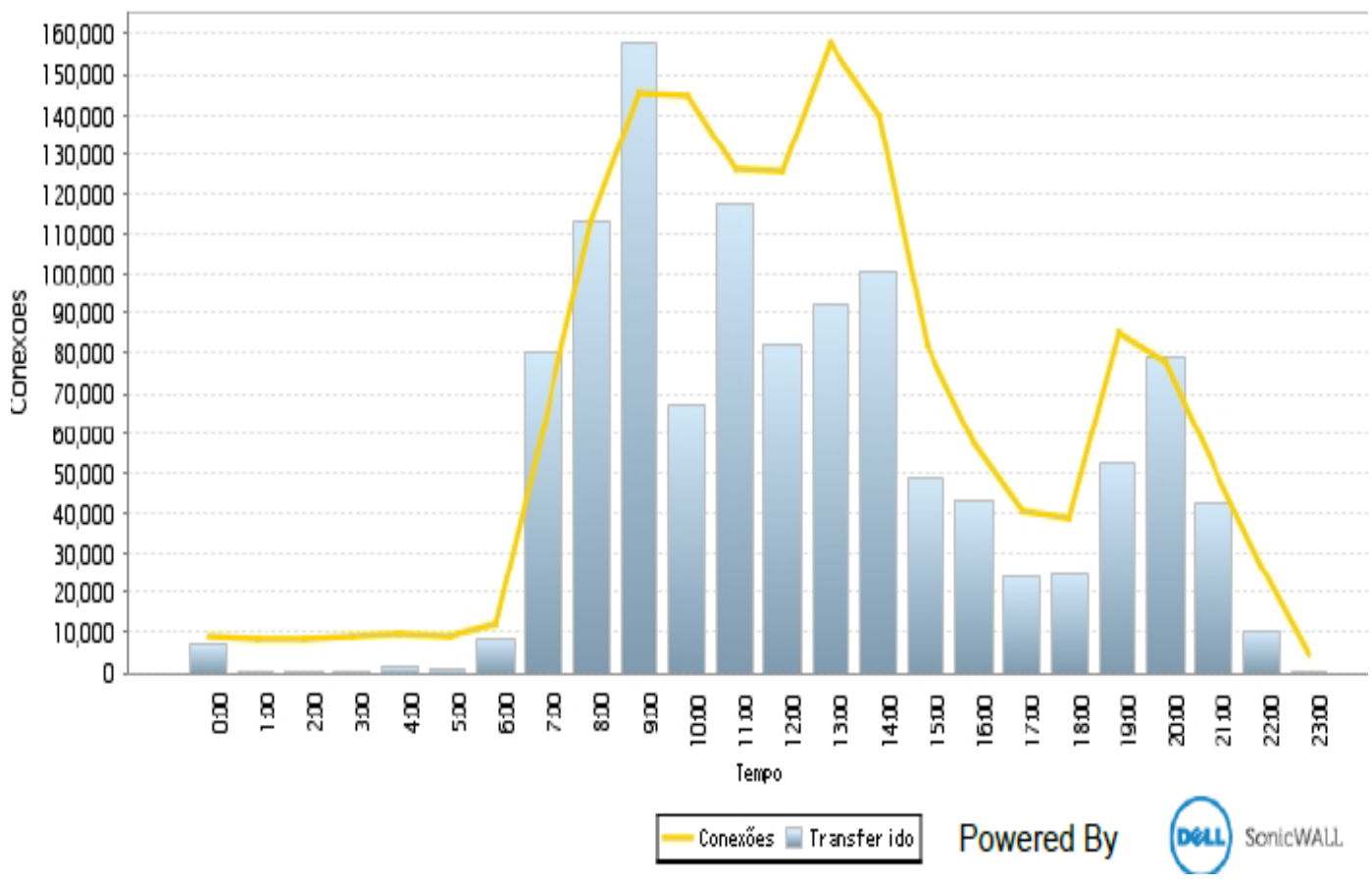

Fonte: Autores, 2020.

Observou-se o mesmo fenômeno configurado na Figura 1, ou seja, igualmente na Figura 2 , temos os picos de utilização da Internet, justamente nos momentos em que os estudantes estavam em sala de aula com a presença dos professores e no transcorrer das referidas aulas presenciais. Senão vejamos, observa-se na quarta feira a ocorrência de picos de utilização da Internet nos períodos de 8 e 9 horas; 11 horas e 14 horas, bem como às 20 horas no período noturno. Mais uma vez, percebe-se uma preponderância de uso da Internet pelos estudantes, 
nos períodos em que estão ocorrendo as aulas presencias, isto, mesmo com o uso dos telefones celulares e o acesso à Internet estarem proibidos em sala no período das aulas.

Observemos no gráfico abaixo (Figura 3) o comportamento referente à sexta feira, no sentido de se evidenciar a existência de um padrão, quanto aos períodos de utilização para o acesso à Internet.

Figura 3 - Gráfico relativo ao uso da internet no dia 14 de setembro de 2018 (Sexta Feira) em um Campus do Instituto Federal

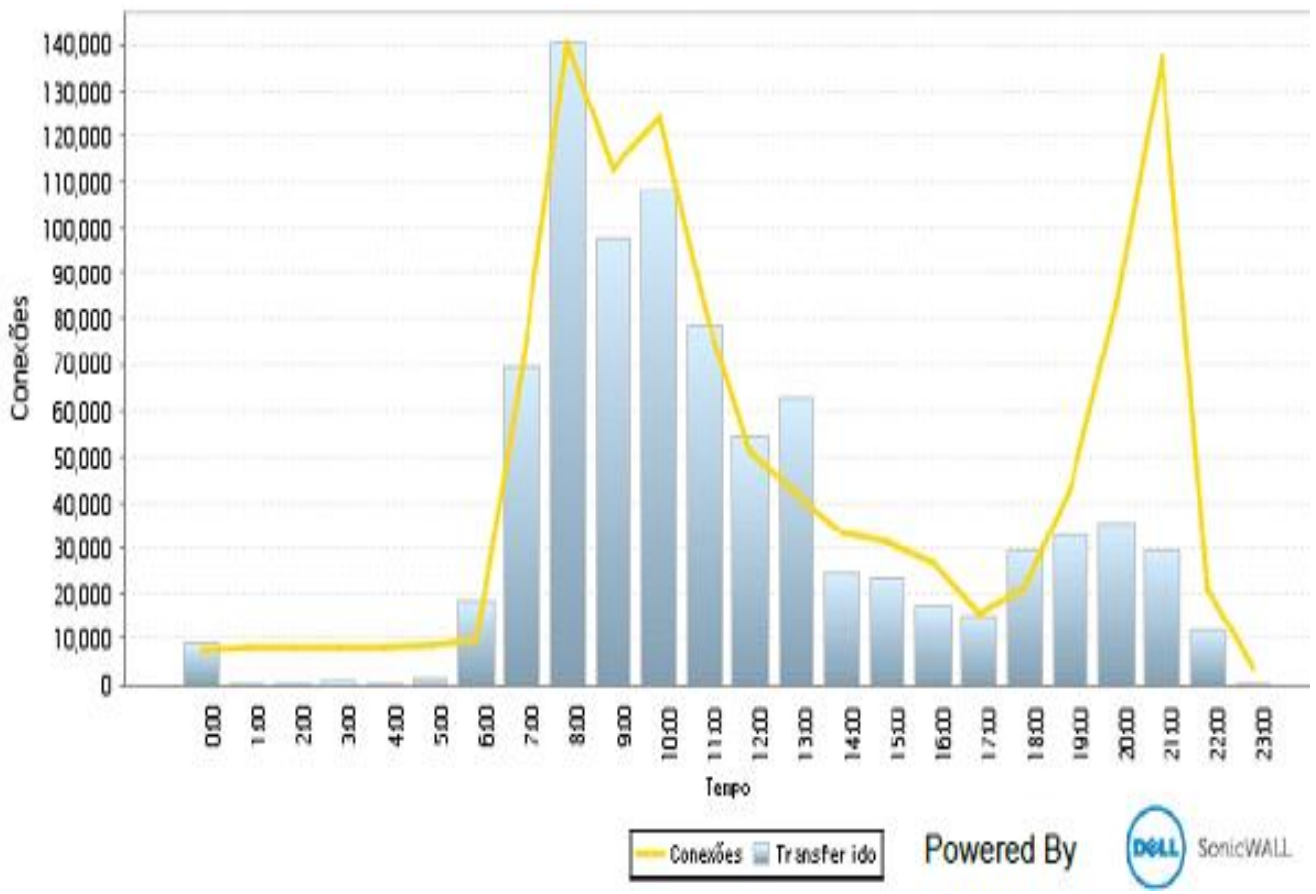

Fonte: Autores, 2020.

Os picos mais altos para a manhã foram alcançados nos períodos de 8 e 10 horas, compreendendo da mesma forma anteriormente observada os tempos escolares destinados às aulas presenciais. De acordo com a organização do campus não ocorrem aulas na sexta feiras à tarde e o período de maior uso da noite é novamente às 20 horas. É sabido que o período noturno daquele tem menos estudantes, no entanto, mesmo com menor intensidade do que outros dias da semana, o período mais utilizado foi às 20 horas, novamente em intervalo correspondente ao período de aulas presencias.

Outra situação que se destaca e fornece confiabilidade à análise dos gráficos, é que à guisa de grupo controle para a pesquisa, no período da tarde de sexta feira, não ocorrem aulas presenciais no campus pesquisado. Considerando esta informação, o comportamento em relação ao uso da Internet no campus, pelo menos no turno matutino, deveria ser no mínimo, todos os dias igual ao registrado na tarde de sexta feira, podendo oscilar para uma maior utilização, apenas nos momentos de intervalo das aulas presenciais, o que não ocorre. Percebe- 
se mesmo que, o uso da Internet está vinculado ao período de aulas presencias no campus no sentido de que, o maior uso ocorre, efetivamente, no período do dia em que ocorrem as aulas presenciais.

Outra questão que se impõe, inclusive em relação aos trabalhos escolares é que, segundo Cruz (2011), a tecnologia da informação aumenta a produtividade individual. Acrescenta este autor que

[...] é inimaginável achar que a maioria das atividades que um ser humano desempenha hoje pode ser realizada sem alguma ajuda da tecnologia da informação. Por mais simples que seja a atividade, existe sempre um dispositivo para tratamento da informação que pode ser utilizado para agilizar as tarefas" (CRUZ, 2011, p. 43).

É possível que esta cultura esteja já de tal forma incorporada ao estudante que seria a seu ver "errado" realizar alguma tarefa proposta pelo professor ou outra pessoa qualquer, sem a otimização das novas tecnologias. Considerando ainda que, contemporaneamente, os suportes de inteligência coletiva do ciberespaço multiplicam e colocam em sinergia as competências. Do design à estratégia, os cenários são alimentados pelas simulações e pelos dados colocados à disposição pelo universo digital (LÉVY, 2010).

Outra situação que pode se apresentar tensa em relação ao uso da Internet em sala de aula é que não é raro o professor ser desafiado em seus conhecimentos por um conhecimento mais pontual e atualizado devido ao acesso a ela pelos estudantes. Essa situação pode colocar os profissionais que não se adaptarem a esta condição em uma posição defensiva em relação ao acesso dos estudantes em aulas à Internet.

Uma questão que também se impõe em relação ao paradigma adotado em sala de aula, tem a ver com o fato de que o conhecimento como abordado em sala de aula está mais relacionado a um raciocínio analógico, tendo em vista que é através do raciocínio analógico que se operam as extensões ou reduções dos conceitos científicos (ex., luta pela sobrevivência e luta de classes. Também como instrumento retórico, a analogia tem grande força persuasiva (Tenório, 1998). A situação conflituosa reside no fato de que esta condição intelectual pode estar superada em uma realidade digital dita disruptiva.

Refletindo sobre nossa condição atual, temos que hoje a capacidade de aprender mais rápido (não simplesmente aprender) é uma vantagem competitiva essencial para as organizações. Não são necessariamente os grandes que vencem, mas também os rápidos (Valente e Mattar Neto, 2007. Assim sendo, as empresas que conseguem se adaptar mais rapidamente às mudanças têm mais chances de sobreviver, de tal forma que as inovações proporcionadas pelas novas tecnologias agregam ao mundo do trabalho uma condição em que 
estruturas rígidas acabam sendo muitas vezes inimigas das empresas estabelecidas, na competição com empresas pequenas (VALENTE e MATTAR NETO, 2007).

Sob esta perspectiva é possível que a escola eminentemente "tradicional" em sua configuração e atuação, que apenas impõe leis proibitivas ao acesso à Internet, podem representar algo efetivamente a ser superado no mercado de trabalho, algo na contramão do que é necessário ao sucesso profissional do estudante. Se efetivamente houver este conflito, nossa posição estará definitivamente comprometida como educadores e encaminhadores dos jovens ao sucesso e ao mercado de trabalho, principalmente em cursos que se dizem profissionalizantes.

É certo que a Internet, segundo Santrosa e Conforto (2012), causa o "empoderamento" do estudante em uma virtualidade que rompe com os limites impostos pela rotina de sala de aula, instituindo um tempo e um espaço que se abre ao acompanhamento mais pontual da família, dando visibilidade ao que vem sendo problematizado em diferentes áreas do conhecimento.

A estrutura extremamente rígida da escola é descrita amiúde na dissertação de Barbosa (2004), indicando que este tipo de estrutura escolar favorece a violência e atitudes rebeldes, de tal forma que podemos depreender que o espírito da escola não pode estar contido, apenas em suas paredes. Existe escola, onde quer que exista discussão, crescimento, exacerbação e essa condição desafiadora imposta pelo acesso dos estudantes à Internet tem de se inserir nesse espírito.

Os educadores não podem se abalar com os desafios sejam eles quais forem, mesmo porque os " [...] educadores são atores sociais que, de forma mais direta e efetiva, impulsionam mudanças na sociedade ao mediar processos de desenvolvimento humano, alterações nas relações econômicas e culturais [...]" (SANTROSA e CONFORTO, 2012, p. 234). De tal forma que, são sobremodo os educadores que, fazem com que o conhecimento aprendido transponha os limites de curso e da escola.

Essa condição de mediação dos professores, alicerçada nos pilares de uma aprendizagem mais significativa, na qual, em suas premissas, segundo Ausubel (2000) e corroborada por Peixoto, Terán e Barbosa (2016), é primordial envolver o discente em situações propostas a partir de sua própria estrutura cognitiva, reorganizando esse seu conhecimento, que uma vez reestruturado, passa ser um "novo conhecimento", que vai se internalizando. Isso, de tal forma que mediante exercício peculiar à espécie humana o limite entre o exterior e o interior 
se altera permitindo a interiorização de muitas situações e circunstâncias em espaços educacionais.

\section{CONSIDERaÇões FinaIS}

Percebe-se que os momentos de maior acesso à Internet ocorrem no período em que os professores estão em sala com os estudantes, mesmo com os telefones celulares sendo proibidos em sala.

Desta forma, contata-se que os estudantes burlam esta proibição e utilizam a todo o momento a Internet sem que os professores disso se deem conta. Tal fato, não deve ser ignorado e precisa ser considerado pedagogicamente no sentido de que é preciso disciplinar o acesso à Internet, educando a mentalidade dos estudantes no sentido de adquirir hábitos mentais que disciplinem o acesso a Rede Mundial de Computadores.

Isto porque o telefone celular com acesso à Internet provoca um "empoderamento" e enorme ampliação da capacidade produtiva e de acesso ao conhecimento pelo discente. É possível que estejamos em um novo limiar educacional para a qual precisamos nos adequar, no sentido de disciplinar os estudantes para o acesso à Internet, por exemplo, não mediante ações proibitivas que tem se mostrado inóquas, mas sobretudo mediante processos pedagógicos que estimulem e eduquem mentalmente esses estudantes, no sentido de estabelecer uma mediação entre o "mundo virtual" com um tempo também virtual e a realidade analógica e física, oriunda ao tempo cronológico.

Como as crianças da educação infantil o estudante precisa compreender que existem tempos mentais adequados a cada uma das atividades. Desta forma, devem dosar a sua atenção entre o professor e o acesso à Internet, de maneira a otimizar as aulas, autodisciplinando o seu acesso às redes sociais e jogos. Existem muitos "momentos" no cotidiano escolar que precisam ter o seu tempo ajustado, delimitado e isto, precisa ser compreendido e treinado.

Dessa forma, o uso do telefone celular como um "portal" de acesso à Internet, pode ao invés de causar distrações e perda do referido tempo individual, otimizar a sua produção, enquanto estudante, bem como a disponibilização de informações a serem debatidas, ampliadas e compartilhadas coletivamente.

Essa maneira de se considerar o que efetivamente ocorre em sala de aula e do que a Internet representa em tempos modernos, pode ajudar no sentido de incorporar essas novas tecnologias no dia a dia educacional. Isto, tendo em vista que, uma vez disciplinado através de 
trabalhos de conscientização, de tempo treinado, em contraposição às proibições, é possível se alcançar frutos educacionais mais profícuos.

Temos, pois, duas alternativas que precisam ser consideradas no sentido de não representarem alternativas dicotômicas, sendo uma aquela que entende este trabalho como ação mais educativa, de criar hábitos mentais adequados de acesso à Internet e focado na disciplina mental. E outra, mais focada no ambiente em que se apresenta o contexto educacional no sentido de se intensificar os filtros de acesso à Internet, reforçando o poder imposto pelas proibições, dentre outras ações gestoras.

\section{REFERÊNCIAS}

AUSUBEL, David. Aquisição e retenção de conhecimentos: uma perspectiva cognitiva. $2^{\mathrm{a}}$ ed. Lisboa: Plátano Edições Técnicas, 2000.

BARBOSA, Márcia Silvana. Silveira. O papel da escola: obstáculos e desafios para uma educação transformadora. 2004. 234 f. Dissertação (Mestrado em Educação) -Universidade do Rio Grande do Sul Porto Alegre, 2004. Disponível em: < https://lume.ufrgs.br/bitstream/handle/10183/6668/000488093.pdf>. Acesso em 28/04/2020.

CASTELLS, Manuel. A Sociedade em rede. $1^{\text {a }}$ ed. São Paulo: Paz e Terra, 2017.

CHIOSSI, R. R.; COSTA C. S. Novas formas de aprender e ensinar: a integração das tecnologias de informação e comunicação (TIC) na formação de professores da educação básica. Linguagem e Tecnologia, Belo Horizonte, v. 11, n. 2 2018, 160-176.

CRUZ, Tadeu. Sistemas de informações gerenciais: tecnologias da informação e a empresa do século XXI. $3^{\text {a }}$ ed. São Paulo: Atlas, 2011.

DAMÁSIO, Antônio.; MOTTA, Laura Teixeira. O mistério da consciência: do corpo e das emoções ao conhecimento em si. $1^{\text {a }}$ ed. São Paulo: Companhia das Letras, 2015.

DARWIN, Charles. The origen of species by means of natural selection. $1^{\text {a }}$ ed. London: John Murray, Albemable Street, 1859.

GERHARDT, Tatiana Engel.; SILVEIRA, Denise Tolfo. Métodos de Pesquisa. $1^{\text {a }}$ ed. Porto Alegre: Editora da UFRGS, 2009.

JEANNEROD, Marc. O Cérebro íntimo. $1^{\text {a }}$ ed. Lisboa: Instituto Piaget, 2005.

JUNIOR, Claudemir Públio. O docente e o uso das tecnologias no processo de ensinar e aprender. Revista Ibero - Americana em Educação, Araraquara, v.13, n. 3, 2018, 10921105.

LÉVY, Pierre. Cibercultura. $3^{\text {a }}$ ed. São Paulo: Editora 34, 2010

LÉVY, Pierre. Inteligência coletiva: por uma antropologia do ciberespaço. $1^{\mathrm{a}}$ ed. São Paulo: Loyola, 2000. 
MORGADO, I. Cómo el cerebro aprende, recuerda y olvida. Alambique didatica de las ciencias experimentales, Espanha, v. 2, n. 68, 2011, 19-29.

OLIVEIRA, Celina Couto de. Ambientes informatizados de aprendizagem: produção e avaliação de software educativo. $1^{\text {a }}$ ed. Campinas: Papirus, 2001.

PEIXOTO, Marco Aurélio Nicolato.; TERÁN, Augusto Fachín; BARBOSA, Ierecê. Aprendizagem em espaços não formais: didática, aprendizagem e epistemologia. In: Temas sobre ensino de ciências em espaços não formais: avanços e perspectivas. Manaus: UEA, 2016. p. 151-163.

SANTROSA, Lúcia Maria Costi.; CONFORTO, Débora. Formação de professores em tecnologias digitais acessíveis. $1^{\text {a }}$ ed. Porto Alegre: Evangraf, 2012.

TENÓRIO, Robinson Moreira. Cérebros e computadores: a complementaridade analógicodigital na informática e na educação. $1^{\text {a }}$ ed. São Paulo: Escrituras, 1998.

VALENTE, Carlos.; MATTAR NETO, João Augusto . Second Life e Web 2.0 na educação: o potencial revolucionário das novas tecnologias. $1^{\text {a }}$ ed. São Paulo: Novatec, 2007.

VYGOTSKY, Lev. A Formação Social da Mente: o desenvolvimento dos processos psicológicos superiores. $1^{a}$ ed. São Paulo: Martins Fontes, 1991.

Recebido em: 15 de maio de 2020.

Aprovado em: 30 de agosto de 2020. 